\title{
Spirituality and its relevance in assistance to patients under palliative care according to experts
}

\begin{abstract}
Background: Palliative care and spirituality are still very little discussed, but when studied and applied they become capable of alleviating some of the dimensions of suffering of man.
\end{abstract}

Objective: To evaluate the understanding of health professionals about the concept of assistance to patients under palliative care and spirituality, as well as the application of techniques to alleviate the spiritual suffering for these patients.

Method: This study used questionnaires in 91 professionals that work in the palliative care area (doctors, nurses and psychologists, chaplains), with at least three years of experience, regardless of gender.

Results: The study shows a divergence in the work of professionals of the multidisciplinary staff, as well as the difficulty in addressing issues of spirituality.

Conclusion: The palliative care and spirituality provide relief to many suffering patients, it is important to have health professionals aligned in concepts and prepared to use it in clinical practice.

Keywords: hospital psychology, assistance, palliative care, spirituality, agency of palliative cares
Volume I Issue $6-2017$

\author{
Beatriz Peres Covello,' Sandra R de Almeida \\ Lopes $^{2}$ \\ 'Graduated in Psychology, University of Presbiteriana Mackenzie, \\ Brazil \\ ${ }^{2}$ Advisor Doctor of Psychology, University of Presbiteriana \\ Mackenzie, Brazil
}

Correspondence: Beatriz Peres Covello, Sã $f \circ$ Paulo Rua Bernardo Josã\%o, 58 Barro Branco, Brazil, Tel 55II 98365-3764, Email biia_peres@hotmail.com

Received: October 06, 2017| Published: November 29, 2017

\section{Introduction}

During our whole life, we spend so much energy on thoughts to obtain what we consider essential for a so called "perfect life" with no suffering. We wish the brand-new car model, fancy clothes that hide the body we are not proud of, save money for plastic surgeries to correct imperfections and overwork. On the opposite way of all that we seek, something unexpected, like a disease can happen. Causing, for some, anger, discouragement, incomprehension, while for others, an opportunity of growth, forgiveness, reunion, redefinition..$^{1,2}$

"When we least expect, a disease surprises us, reminding of our mortal condition. We are not everlasting here, we are not selfexisting and we need one another. This discomfort from the disease, the pain, and suffering, introduces itself surreptitiously through the back door...with no introductions. These become unwelcome guests on this journey, annoying guests that asks us for a seat on the dinner table, at the apex of the feast of life, questioning us, tearing our plans apart, even though we have never asked for it, or be able to express otherwise" (PESSINI, 1990, p.23). ${ }^{3}$

On the last few decades in Brazil, we have seen the progressive ageing of the population, as well as daily raise on Cancer and Chronic Diseases diagnosis (MONTEIRO,1997). ${ }^{3,4}$ Making necessary on the public health system, a new look on these ill. According to data from the Department of Information and Technology of the Common Health System (DATASUS), in 2006, 1.031.691 Brazilians passed away. The deaths from diseases with chronic progression, degenerative or neoplasia, together it's a total of over 725 thousand people that died in Brazil with high chances of intense suffering. Over 690 thousand people passed away in hospitals, and other 224 thousand at home. ${ }^{5}$ The life extension at any cost is dominant and rooted within on our culture. Specially with the raise of technology and devices capable of keeping the body alive for days, months and years. In other words, many mortal diseases were transformed into chronic, raising the patient's longevity, but not necessarily doing the same to the life quality. Therefore, there is an incessant argument to turn the idea that the cure of certain disease must be the main goal of Health Services in general. To do that, there are the palliative care, gathering abilities of a multi-professional staff to help the patient to adapt to changes in life, imposed by the disease, by means of family and patient's reflection to face this life threatening condition. ${ }^{6,7}$

According to the World Health Organization, palliative cares are "active and fully provided to patients with progressive and irreversible disease, possibly lethal, it's essential to control the pain and other symptoms through the prevention and relief of physical, psychological, social and spiritual pain". ${ }^{8}$ On this context, spirituality plays a role of extreme importance. Pessini Bertanchini (2006), refers to the etymology of the word Spirituality, that means breath of life and finding sense. Spirituality, on the search for tendencies, goes beyond the traditional religious dogmas. ${ }^{9}$

\section{Materials and methods}

The survey on area experts has the approval of the Ethical Commission and it's registered at Plataforma Brasil under the number CAAE 51291315.0.0000.0084..$^{10}$ The objective is to evaluate the understanding of health professionals about the concept of patient assistance under palliative care and spirituality, as well as application of techniques to relief patients from spiritual suffering. ${ }^{11}$ To represent it, it was used an open-ended questionnaire, built from an ordered series of questions, which were answered in writing, in the absence of interviewer. This research with mixed character - qualitative and quantitative - used a sample space of 91 professionals (Figure 1) that works with palliative care (doctors/nurses/psychologists/chaplains), with at least three (3) years of experience, no gender distinctions. ${ }^{12-14}$ 


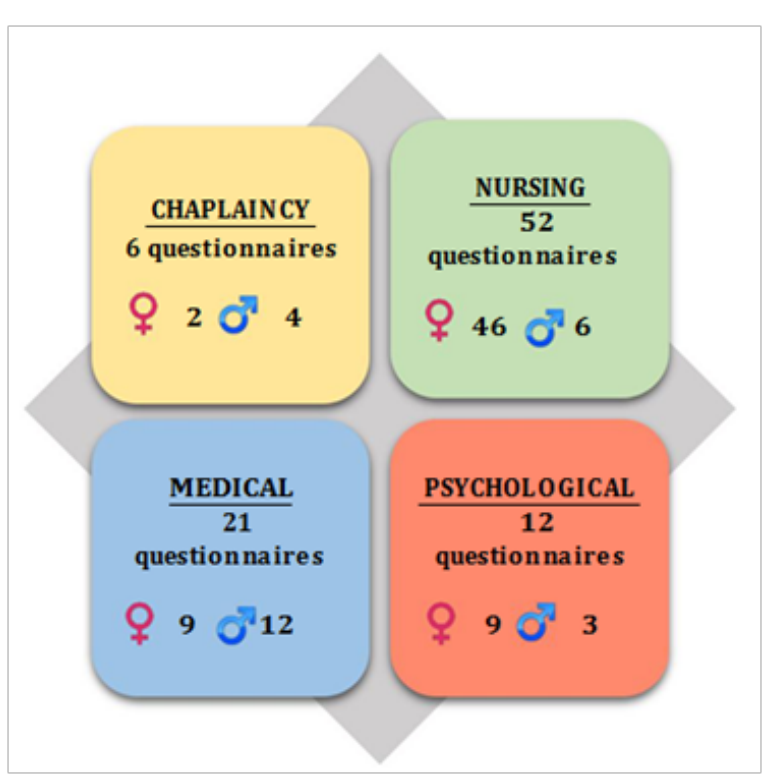

Figure I Quantity and gender of professionals interviewed.

\section{Analysis criteria}

To analyze the answers presented by the interviewed, we used as Theoretical Frame the date described, by area of expertise, by the National Agency of Palliative Cares (ANCP). For nursing, the Palliative Care is inherent to everyday practice. To ally science and art to serve a need that sustain, support and comfort is a task to every nursing professional, since birth assistance to diagnosis of an advanced stage disease, fortifying and becoming even more present on the terminality, and continuing during the morning period..$^{15,16}$

The abilities of a nurse should be turned to a systematical evaluation of symptoms; aid a multi-professional staff to stablish priorities for each patient, to a dynamical family interaction, especially to reinforce clinical orientations, in order to achieve therapeutic goals designed by the multi-disciplinary staff. It is sensitive care and education that demands the actions of physical and emotional proximity, to make sure the orientations are followed. To understand the role of the psychologist on the multi-professional staff, it is important to understand the definition of "Total Pain", developed in 1960 by the British doctor Cecily Saunders, which implies directly to the psychologist's actions, as it comes along, together with organic reasons, the emotional factor as an aspect related to pain. The Idea of Total Pain admits that no biological organism is independent from the psychological state. In Palliative Care, the definition of "Total Pain" expands to "Total Symptoms", as the there are other symptoms present, such as anxiety, depression, sleep disorder, vomit, dyspnea etc. ${ }^{17,18}$

According to the psychoanalytical theory, the disease and its whole context are interpreted by the ill at light of its speech, meaning the patient's affections and beliefs (conscious or unconscious). Considering that, the psychologist offers his clinical listening to those who wish to talk, searching for this way of benefit the elaboration of perceptions related to the disease. According to the patient's point of view, it can contribute to reorganize the self-image once distorted by the disease and treatment. For such, psychological support to patient and family should initiate as early as possible. The quality of the relationship between the patient and those in charge of the patient's treatment can benefit or interfere adversely during the illness, death and grief. For that reason, Palliative Care's attention to the patient's family is another guider to team's actions. The Palliative doctor must give clinical diagnosis. Must know the disease, its natural history, treatments, which evolution of the disease is to be expected according to each patient. ${ }^{19-23}$

If necessary, must be in touch to other medical expertise that has or is still treating the same patient, to discuss certain specifics conducts. It's also the doctor's responsibility to propose treatments, medications or not, suitable to patient's moment of life. In certain way, to assure not only relief from uncomfortable symptoms, but also the dignity of life until the end. Avoiding, this way, procedures that could raise patient's suffering. Perhaps the main task of the doctor on a Palliative Care team is to coordinate the communication between staff, patient and family. The patient and family wishes to hear from the doctor about the diagnosis, the therapeutic proposal, and about the disease's prognosis. Under no circumstances should the Doctor designate to any other member of the staff the responsibility to talk to the patient and family about these aspects directly related to the disease. ${ }^{13}$

It's also very important for the doctor to communicate effectively with the staff about these aspects, so that when questioned by the patient or family, all answers are aligned and everyone must know how to interact and talk to them. Therefore, the patient's therapeutic plan must be a staff's joint task, with an active participation of the patient and its family.

Yet according to Consolim (2012), the doctor is a part that facilitates the balance of the staff so they can help the patient to be autonomous. Consequently, the choices and decisions made are shared with the patient, family, and Palliative Care staff so they all share responsibilities on promoting a healthy life, fulfilling the purpose of taking care of the patient in an individualized and holistic way, focusing on the wellbeing and life quality, regardless how evolved the disease is. ${ }^{24}$

At last, the role of the chaplain it is not to impose a religion, or principles. It's important to understand that when we talk about religion and spirituality, there's a misunderstanding association to organized religious communities, with rules, dogmas, ceremonies and commandments. Spirituality tends to be felt more as something from within, spontaneous, and is related to love, inspiration, integrality, deepness and mystery, on a more personal character. For a holistic patient and family care, are necessary: the daily individual spiritual care will bring the ill and the caregivers: attentive listening, deep reflections about existential matters, confronts and challenges about the purpose of life, forgiveness, scores settlement, eternal life, quality and utility of life. ${ }^{13,21}$

To offer spiritual care as part of a major health care is to allow to the beneficiary to express his feelings and emotions, talking plainly about life and death, and helping him to participate in every decision related to his treatment and final wishes. The Palliative care appreciates that the "spiritual and emotional cure" can really happen when the physical cure or recovery happens to be impossible. But many patients severely ill or in terminal stage admit finding purpose in their life, fulfilling the holes that they have never seen it before. The medical staff will also benefit from the chaplain's support in situations of personal stress or an eventual loss of a patient. Even on the daily task, this support helps them to feel safer for taking decisions on bioethical matters, involving the patient's end of life dilemmas. ${ }^{19}$ 


\section{Results and discussion}

The first question brought up was about the understanding of Palliative Care.

We got answers such as:

i. "Palliative are embraces the whole care process, comfort, and relief that we could give the patient on its terminal stage" (sic).

ii. "To me, Palliative Care is a way to take care of a patient in the terminal stage, providing comfort, affection, emotional support to deal with the disease and death" (sic).

iii. "To comfort terminal stage patients" (sic).

iv. "They are cares to patients that are in terminal stage" (sic).

v. "Consists on the assistance provided by the medical staff, aiming to improve patient and family's life quality, during the whole process" (sic).

vi. "Attention to physical, emotional, psychosocial and spiritual aspects of patients with progressive and irreversible chronic diseases, as well as the support to family members, focusing in life quality" (sic).

vii. "They are cares that engages a multi-professional staff with the objective to minimize physical, mental, spiritual and social suffering of a patient and its family when facing a terminal disease. It must initiate as soon as possible, to avoid greater suffering e allow them to enjoy a good life quality on the broadest sense, physical, mental, social and spiritual. Every doctor should have this knowledge to share with his patients in cases which medicine will no longer be able to ensure a cure" (sic).

viii. "Palliative Care is one of the ways to bring back the individual to his entirety on moments where the speech of medicine no longer reflects what Real-Death is. It is a proposal of cares the recover the human experience in its completeness, in other words, in its multidimensionality, but also on its finiteness, and time limitation" (sic).

ix. "It is a field of assistance in multi-professional health that considers the importance of a holistic care on patients with diseases threatens life maintenance" (sic).

So, it is possible to identify in a few passages above, that the concept of Palliative Cares is still very rooted as cares that initiate at the end of life. This idea contradicts the main definition of Palliative Care: to take holistic care during the whole processes, initiating with the diagnosis. On the other hand, we found reports that emphasize the importance of a multi-professional staff and the need to take care of physical, mental, spiritual and social suffering of each individual separately. $^{25}$

Subsequently, was asked about the comprehension of the concept of spirituality in Palliative Care, ${ }^{18}$ we got answers as such:

i. "It is to prepare the patient to a quiet and peaceful death, regardless the religion" (sic).

ii. "I believe it's a belief. Faith unique to each person" (sic).

iii. "Patients who has history with spirituality over their lives, faces the end of life in a more peaceful way because they believe in soul's immortality when the body fades away. Spirituality is the feeling of transcendence, is to understand life not only on its matter, we have a spirit that cheers our body, that we should take care of it as much as we do on our material side" (sic).

iv. "Spirituality in this area is the group of beliefs of each patient and/or family members, as well as the medical staff recognition of the dimension of human's spirituality, that needs assistance and interfere, in certain way, on social and emotional area. For us, particularly, is about our relationship with God, that certain person has, or might have, to face an aggressive, and with no possibility of cure, disease" (sic).

v. "Spirituality is one of the elements of Palliative Care that considers its relevance to patient's well-being" (sic).

In this case, the answers brought by professionals demonstrate a misinterpretation of definitions, assimilation of spirituality to the moment of death and personal beliefs. ${ }^{26}$ When questioned on their approach about spirituality with their patients, they say:

i. "I try not to understand the relation that the patient/family about their spirituality and how it impacts the way they deal with the disease" (sic).

ii. "I don't approach. I'm no believer, why should I question why the other has no faith either ?"(sic).

iii. "I don't feel ready to approach this subject with my patients" (sic).

iv. "I always tell them that the cure comes from God's will. I tell them to pray" (sic).

v. "I try to improve the considerations brought by patients and their families about the meaning of their life for them, what they think about life after death and to look to the past" (sic).

vi. "First I ask about their beliefs, then I tell them to rate their faith from 1 to $10 "$ (sic).

vii. "I don't provide opportunities for my patients to approach me to talk about this; my emotional is not ready to deal with that" (sic).

Some dangerous professional behaviors exposed on the questionnaire come from the idea of promoting certain religion or ritual that assists the individual during the process. However, these professionals end up exposing their own beliefs letting aside the subjectivity of the individual and the correct role inside the institution and the multi-professional staff.

Another topic observed throughout the questionnaires is the unpreparedness of professionals on the approach on matters related to spirituality. We can assume, in this case, that changing this scenario needs the professional staff to invest on dialogs on their own personal matters, limitations, anxieties, and the improvement on dialog approach techniques.

When questioned if religion and spirituality have the same definition, ${ }^{27}$ our volunteers answered:

i. "No. Religion is about practices and convictions for each group. Someone can say they belong, for example, to Catholicism, without even know this religion quit well, which would still be different then truly experience a relationship with God" (sic). 
ii. "Religion is about dogmas/structures. Spirituality is something personal the is to be found through religion (or not)" (sic).

iii. "Spirituality is not Religiosity. The first exists independent from the second. Religiosity is dogmas, beliefs, rituals. Spirituality is the divine conscience that inhabit in our mortal body" (sic).

iv. "Yes, because is throughout both that a person fortifies, believes in a purpose and get stronger. Believe in God and eternal spiritual life" (sic).

v. "I believe so, one connects to the other" (sic).

vi. "Yes, you are spiritualized when you have a religion" (sic).

On this subject, we cross again on personal beliefs. Some believe that spirituality has the same definition as religion, others say that they complete each other, and for last, some believe that the definitions are different. On the first chart (Table 1) the results show us that most the interviewed believes on the importance of spirituality on Palliative Care. However, three other nursing professionals say otherwise, claiming:

i. "Not all are helped for believing in something spiritual, sometimes it bothers them even more" (sic).

ii. "People don't like to talk about spirituality" (sic).

iii. "I've never experienced anything that can prove this importance" (sic).

Table I Professionals and answered

\begin{tabular}{lll}
\hline Do you believe in the importance of spirituality on palliative care? \\
\hline & Yes & No \\
Chaplaincy & 6 & 0 \\
Nursing & 50 & 3 \\
Medical & 21 & 0 \\
Psychological & 12 & 0 \\
\hline
\end{tabular}

On Table 2, we can see that more than $50 \%$ of the nursing sample does not approach spirituality with their patients, and justify:

i. "I don't approach because we work in a place with no conditions or time, we are overloaded and with no time" (sic).

ii. "I wait for them to show signs that they believe in that, if not, I don't talk about it" (sic).

iii. “This is hard, I might talk about it and they don't believe in it. I can't put my faith together with my work" (sic).

iv. And the only one that answered saying that sometimes she approaches, she writes:"I only approach when I feel touched by something grater, I say that God is above all" (sic).

Table 2 Professionals and answered

\begin{tabular}{llll} 
Do you approach the topic spirituality & with your patients? \\
\cline { 2 - 4 } & Yes & No & Sometimes \\
\hline Chaplaincy & 6 & 0 & 0 \\
Nursing & 32 & 20 & 1 \\
Medical & 14 & 6 & 0 \\
Psychological & 12 & 0 & 0
\end{tabular}

The medical team claims:

i. "I don't approach, talk only about the disease, that's what they expect to hear from me" (sic).

ii. "I believe that is not quite my role, I handle things that, as a doctor, I am able to solve, approach it is to mix Science and Religion" (sic).

iii. "I'm not used to approach it, there's not even time left for that" (sic).

In face of these answers, is possible to understand that the majority professionals believe in the importance of spirituality on Palliative Care, but many do not approach the subject with their patients. Once more, we could relate it to their unpreparedness that causes insecurities on the approach.

On Table 3 the point of resistance, presented by professionals from the sample show similar experiences, all related that avoids the subject or believes that the disease is a punishment not deserved.

Table 3 Professionals and answered

\begin{tabular}{llll}
$\begin{array}{l}\text { According to your experiences, is there more resistance or } \\
\text { acceptance about spirituality? }\end{array}$ & Acceptance & Resistance & Both \\
\hline $\begin{array}{llll}\text { Chaplaincy } & 4 & 2 & 0 \\
\text { Nursing } & 30 & 10 & 1 \\
\text { Medical } & 17 & 2 & 0 \\
\text { Psychological } & 1 & 9 & 0\end{array}$ \\
\hline
\end{tabular}

This resistance can also be seen by professionals according to the taboos that surround the topic and the difficulty of the staff, in general, to talk to their patients. But those who realize the presence of both on the patient's dynamic, describes that during the processes the denial is a strong hindrance, but slowly over the treatment, the acceptance makes the patient more willing to talk about certain things.

On Table 4 is possible to identify that the perception about change on the resistance about spirituality is not realized in every area. The chaplaincy justifies:

i. "Not always, but many times, yes! In general, they invest on spirituality, but in a few cases, the more they suffer, the more they get discouraged and disbelieved" (sic).

ii. "A little, a few can change. But depends how much they change physically during the process. In other words, the level of suffering and tiredness of the treatments" (sic).

Table 4 Professionals and answered

\begin{tabular}{llll}
\hline $\begin{array}{l}\text { The resistance to spirituality changes during time, in other } \\
\text { words, close to death? }\end{array}$ & Yes & No & Not Always \\
\hline & 2 & 0 & 4 \\
\hline Chaplaincy & 31 & I & 4 \\
Nursing & 8 & 1 & 8 \\
Medical & 0 & 4 & 7 \\
Psychological & & &
\end{tabular}


At nursing, it is possible to understand some professionals that also shared that they not always talk to their patients change when close to dying.

i. "Sometimes they even talk about it, but at the same time they are still angry. They don't think It's fair to be punished by something greater" (sic).

In human medicine, we also observed similar point of views of the other teams:

i. "Not always, because those under palliative care don't believe in a cure anymore, therefore God, neither their family members" (sic).

ii. "Depends on the way they led their lives, and how the deal with Death. If it was well explored during life, some, at the end, accept spirituality easier. Even if before they got angry with God" (sic).

On the psychiatric staff, most of them reports that they realized, most of the time, this change, "In some cases, yes. The proximity to death can bring to questioning things about life, existence, just as feelings of helplessness and voids inside. I realize that some patients and family members, through time, starts to consider thinking about spirituality"28 (sic).

The sample illustrated on Table 5, the nursing and medical teams showed data that caught our attention for the significant number of professionals that does not take into consideration that the palliative care and spirituality brings significant changes on their personal life. All in a nutshell, they justify the systematic search to always separate daily work practices from their personal life.

Table 5 Professionals and answered

\begin{tabular}{|c|c|c|}
\hline \multicolumn{3}{|c|}{$\begin{array}{l}\text { Do you consider that dealing with palliative care and } \\
\text { spirituality on your daily work routine has brought any } \\
\text { significant change in your personal life? }\end{array}$} \\
\hline & Yes & No \\
\hline Chaplaincy & 6 & 0 \\
\hline Nursing & 28 & 15 \\
\hline Medical & 10 & 11 \\
\hline Psychological & 12 & 0 \\
\hline
\end{tabular}

On Table 6, the answers are personal, and some individuals of the nursing team shows that the spirituality does not provide better life quality on near death patients, pointing that:

i. "No. Believing in something does not change the result!" (sic).

ii. "I believe not. The life quality of a patient near death is personal. Not always what is good for my life quality is necessarily good for yours. That's why spirituality won't always help" (sic).

On the last Table 7, when questioned if they believe that new kinds of interventions should be studied, the nursing and psychology staffs shows that in some cases they believe it has no need to be studying new interventions. Both justify saying that spirituality is something personal and that beliefs should be from the patient itself, and cannot be explored in studies as a way of intervention. The three participants from the medical team does not know if these interventions could ever be studied. They say that spirituality must be studied carefully, so it can bring actual benefits to patients, without imposing or obligating it on treatment.

Table 6 Professionals and answered

\begin{tabular}{lll}
\hline $\begin{array}{l}\text { In your opinion, does spirituality provides a better life quality on } \\
\text { the final stages of life? }\end{array}$ & Yes & No \\
\hline & 6 & 0 \\
\hline Chaplaincy & 43 & 6 \\
Nursing & 21 & 0 \\
Medical & 12 & 0 \\
Psychological & 12 & \\
\hline
\end{tabular}

Table 7 Professionals and answered

Do you believe that new interventions should be studied in case spirituality has proven relevant?

\begin{tabular}{llll}
\hline & Yes & No & Don't Know \\
\hline Chaplaincy & 6 & 0 & 0 \\
Nursing & 41 & 6 & 0 \\
Medical & 18 & 0 & 3 \\
Psychological & II & 1 & 0 \\
\hline
\end{tabular}

\section{Conclusion}

There is an urgent need to expend the main concepts of Palliative Care. It is necessary to root this information by degrees with health professionals and later with patients and family members, aiming to demystify that palliative cares are only in terminal stage disease. ${ }^{24}$ On the other hand, as mentioned during the article, the palliative cares start earlier, to assure life quality during the whole process. There are still few services related to Palliative Care that are offered in Brazil. Smaller yet, is the number of those who offer attention, based on high quality scientific criteria. But if health institutions invest on graduating palliative care professionals will lower the patient and family members' suffering, minimalizing the cost needed for the care, because it will prevent from unnecessary appointments and hospitalizations to control such symptoms. ${ }^{18}$

It is important to emphasize that every professional is, above all, a human being and can benefit from this self-knowledge with the daily practices on Palliative Care. All in all, the guideline taken by the professionals is quite divergent. Besides, in a few questionnaires, are mentioned the importance of a multi-professional team in the patient's treatment process. Otherwise, the job sometimes seems to be individualized, and the cases littles discussed between areas.

\section{Final considerations}

To change the current scenario, it is necessary that professionals working on palliative care has an honest relationship with themselves when it comes to life and death, their own philosophical position, religion, and spiritual. Thus, it is possible to achieve a balance over your doubts while they present themselves during the patient's care and treatment. At last, it is essential to look to an individual on its totality, in other words, in all their dimensions: physical, emotional and spiritual. The same way that the team must gather to discuss the cases and what measures should be taken. So, it facilitates patient's care, working the team's own limitations. A professional helping 
on another's difficulty, by changing experiences and theoretical knowledge. ${ }^{28}$

\section{Acknowledgements}

I thank everyone that, directly or indirectly, was part of my graduation, especially Professor Sandra R. de Amleida Lopes that helped me so much to write this article.

\section{Conflict of interest}

The author declares no conflict of interest.

\section{References}

1. http://www.apcp.com.pt

2. Araujo JA, Leitão EMP. The Patient Caregiver in Palliative Care: Overload and Challenges. Magazine universitary hospital Pedro Ernesto, UERJ, Brazil: Springer; 2012.

3. Brand P. Coping with a chronic disease: the role of the mind and spirit. Patient Educ Couns. 1995;26(1-3):107-112.

4. Campbell ML. Nurse to nurse: cuidados paliativos em enfermagem Porto Alegre(RS): AMGH: Springer 2011. 296 p.

5. Cassel EJ. The nature of suffering and the goals of medicine. $N$ Engl $J$ Med. 1982;306(11):639-645.

6. Cooper-Effa M, Blount W, Kaslow N, et al. Role of spirituality in patients with sickle cell disease. J Am Board Fam Pract. 2001;14(2):116-122.

7. Gomes AMR. Spirituality does not approach death. Global Nursing; 2011.

8. Harrison MO, Edwards CL, Koeing HG, et al. Religiosity/spirituality and pain in patients with sickle cell disease. J Nerv Ment Dis 2005;193(4):250-257.

9. Hudson T. Measuring the results of faith. Hosp Health Netw. 1996;70:2228.

10. KEMP C. Spiritual care interventions. In: Ferrel BR, Coyle N editors. Textbook of Palliative Nursing. 2nd ed. New York, USA: Oxford University Press; 2006. p. 595-604.

11. Koeing HG. Religion, spirituality, and medicine: how are they related and what does it mean. Mayo Clin Proc. 2001;76(12):1189-1191.

12. Koeing HG. Religion, spirituality, and medicine: research findings and implications for clinical practice. South Med J. 2004;97(12):1194-200.

13. Martins AA. Consciousness of finitude, suffering and spirituality. The world of health. 2007;31:174-178.
14. Moreira-Almeida A, Lotufo Neto F, Koeing HG. Religiousness and mental health: a review. Rev Bras Psiquiatr. 2006;28(3):242-250.

15. Moreto MLT. What can an analyst in the hospital. Psychologist's House, São Paulo, Brazil: Springer; 2001.

16. Maronesi Letícia Carrillo, Silva Nilson Rogério da, Cantu Silvana de Oliveira e Santos, et al. Stress and overload indicators in formal and informal caregivers of cancer patients. 2014;14(3):877-892.

17. Matzo ML, Sherman DW. Palliative care nursing: ensuring competence care at the end of life. Geriatric Nursing. 2001;22(6):288-293.

18. Okon TR. Spiritual, religious, and existential aspects of palliative care. $J$ Palliat Med. 2005;8(2):392-414.

19. Oliveira RA. Palliative Care. Regional council of medicine of the state, São Paulo, Brazil: Springer; 2008.

20. Peres Mario FP, Arantes Ana Claudia de Lima Quintana, Lessa Patrícia Silva, et al. The importance of the integration of spirituality and religiosity in the management of pain and palliative care. Rev psiquiatr clín. 2007;34(suppl 1):82-87.

21. Puchalski C. Task force report: spirituality, cultural issues, and end of life care. Assoc of Am Med Colleg, Contemporary issues in medicine, communication in medicine, medical school objectives project; 1999. p. 25-26.

22. Rodrigues IG, Zago MMF, Caliri MH. An analysis of the concept of palliative care in Brazil. World Health. 1995;29(2).

23. Vera Lucia Rezende, Sophie Françoise Mauricette Derchain, Neury José Botega, et al. Depression and anxiety in caregivers of terminally ill women in breast and gynecological cancer. Rev Bras Ginecol Obstet. 2005;27(12):737.

24. Saunders C, Sykes N. The management of terminal malignant disease 3rd ed. London, UK: Edward Arnold; 1993. 305 p.

25. Sinclair S, Pereira J, Raffin S. A thematic review of the spirituality literature within palliative care. J Palliat Med. 2006;9(2):464-479.

26. Skilbeck JK. End of life care: a discursive analysis of specialists palliative care nursing. J Adv Nurs. 2005;51(4):325-334.

27. Wachholtz AB, Pargament KI. Is spirituality a critical ingredient of meditation? Comparing the effects of spiritual meditation, secular meditation, and relaxation on spiritual, psychological, cardiac, and pain outcomes. J Behav Med. 2005;28(4):369-384.

28. Wachholtz AB, Keefe FJ. What physicians should know about spirituality and chronic pain. South Med J. 2006;99(10):1174-1175. 